\title{
Design of A New Type Thrust Measuring System for Micro-turbojet Engine
}

\author{
Hongji Zhu ${ }^{1}$, Farong $\mathrm{Du}^{1, *}$, Shuai Zhao ${ }^{1}$, Zheng $\mathrm{Xu}^{1}$ and $\mathrm{Zhan} \mathrm{Lv}^{1}$ \\ ${ }^{1}$ Beijing Laboratory for General Aviation Technology, Beihang University, Beijing 100191, China \\ *Corresponding author
}

\begin{abstract}
In order to measure thrust of the micro-turbojet engine accurately, a new type of thrust measurement system was designed. The measuring system includes test bench, load cells, data acquisition modules and computer. The test bench utilizes a suspended test bed, which is different from the test bench supported by springs for aero-engine. It has simple structure and is easy to install and debug. The errors of the measuring system are analyzed from the influence factors of the thrust line and the error of the test instrument. At last, the axial loading static calibration method of the measuring system is introduced. Calibration results show that the thrust measuring system can achieve accuracy of $\pm 0.33 \%$, which is satisfied with the requirement of the test.
\end{abstract}

Keywords-micro-turbojet engine; thrust measuring; test bench; static calibration

\section{INTRODUCTION}

With the development of unmanned aerial vehicle technology, more and more micro-aeroengines are demanded, and the micro-turbojet engine with good performance and low cost has become a research hotspot. Depending on the magnitude of the thrust, a turbojet engine with thrust less than $1000 \mathrm{~N}$ is often classified as micro-turbojet engine [1]. It is important to measure the thrust accurately during engine testing and delivery, because thrust is the core parameter of microturbojet engine.

Many scholars have carried on researches to the turbojet engine thrust measurement. Yang Quanyan designed a highprecision measuring system with AT89C52 single chip processor, and experiment results show that the system can greatly improve measuring precision [2]. Wang Runming and Luo Yi have analyzed the impact of different movable stand support on rig rigidity coefficient, and the relationship between engine thrust, support of movable stand and rigidity coefficient of test bench [3]. Zhang You, Wu Feng and He Peilei studied the factors and function of principle errors which influenced thrust measurement test bench system, that supported by spring for aeroengine, established mechanical model based on thrust eccentricity assumption, and analyzed the principle errors of aeroengine test bench by using both theoretical analysis and simulation [4]. Quan Yazhou designed a six degrees of freedom thrust measuring platform, and analyzed the whole ground test bench about the micro turbine [5].

At present, the thrust measuring test bench studied by researchers is typically used for aero-engine with large thrust. The test bench is supported by springs, consists of a fixed frame, a movable frame and spring pieces. The fixed frame is rigidly connected with the base, while the movable frame is arranged on the fixed frame by spring pieces, and the turbojet engine is mounted on the movable frame. When testing, the engine thrust can be calculated by the small deformation between the fixed frame and the movable frame [3]. This type of test bench is widely used in thrust measurement of turbojet engines which have large thrust. However, it is complex and have low accuracy for the micro turbojet engines with smaller volume and thrust. Also, many manufactures of micro turbojet engine do not have the conditions to make such a test bench, which bring trouble to the development of the micro-turbojet engine. This paper designs a new kind of micro-turbojet engine ground test bench thrust measurement system, which effectively solved the problems of thrust measurement for the micro-turbojet engine.

\section{THRUST MEASURING SYSTEM}

\section{A. The Measuring System}

The micro-turbojet engine thrust measuring system includes test bench, load cell, data acquisition modules, computer and so on [6]. The test bench utilizes a suspended test bed described as follows. The S-type sensor whose model is CFBLSM-100Kg is used as load cell. The ADAM-4018 and ADAM-4520 are used as data acquisition modules. And thrust measurement software is written by using VC ++ and LabVIEW which designed by National Instruments. During the test, the sensor converts the change of thrust into electric signal, then the electric signal is converted into digital signal through the data acquisition modules and transmitted to the computer at the same time. Finally, real-time monitoring and data processing of engine thrust can be done with the software written already. The system is shown as Figure I .

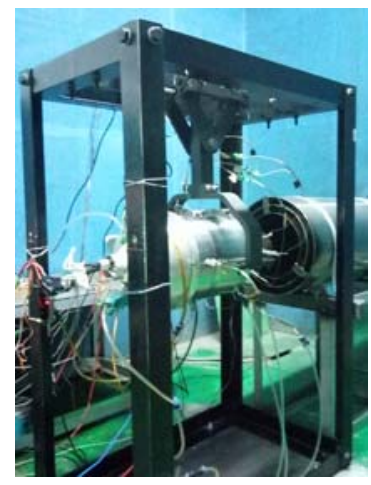

FIGURE I. THRUST MEASURING SYSTEM. 


\section{B. The Test Bench}

The structure of the test bench is shown in Figure II, includes a fixed frame, a lever, a roller, two sliders and so on. The lower end of the lever is connected with the micro-turbojet engine through a clamp. The upper end of the lever is equipped with a roller, which is sandwiched between two sliders that can only slide in the horizontal direction along the guide rails. The two sliders are connected to the load cells respectively. Before the test, the preload force should be applied to the load cells according to the magnitude of the thrust measured. By the principle of leverage, the upper end of the lever will get the corresponding force when engine thrust acts on the lower end of the lever. At the same time, the force on the upper end of the lever is converted into the force along the horizontal direction by the contact of the roller and the sliders, acting on the two load cells.

The force balance is maintained along the center axes of the two sensors. Before the experiment, assuming that the readings of two load cells were $F_{L}$ and $F_{R}$, then:

$$
F_{2}+F_{R}=0 \text {. }
$$

During the test, supposing the readings of two load cells are $F_{2}^{r}$ and $F_{R}^{s}$, the ratio of the lower arm of lever to the upper arm is $\mathrm{K}$, and the thrust of engine is $\mathrm{T}$ :

$$
\mathrm{F}_{L}^{r}+\mathrm{F}_{N}^{r}+K * T=0
$$

So, we can get the thrust,

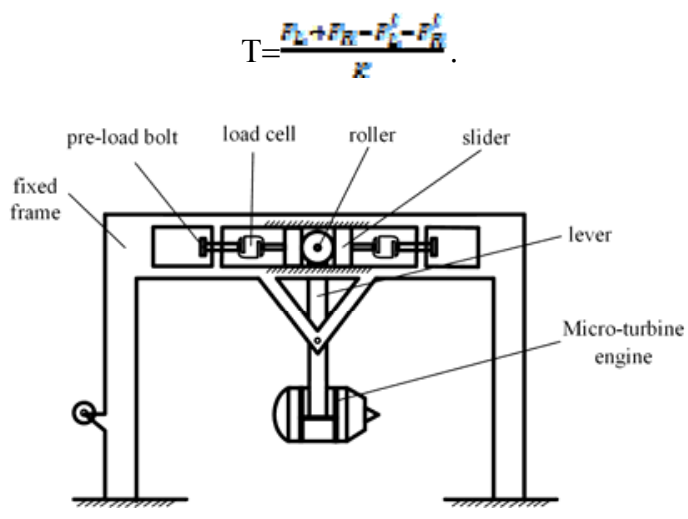

FIGURE II. STRUCTURE OF THE TEST BENCH.

\section{ERROR ANALYSIS}

It is an important technical indicators of measuring accuracy to determine the merits of the test bench. The accuracy of the test bed depends mainly on random error and systematic error. Random error means an error in measurement caused by factors that vary from one measurement to another. Random error is mainly caused by random factors, such as changes in test conditions, engine stability, and laboratory personnel operations. Random errors can be reduced by repeated measurements and appropriate data processing. Unlike random errors, systematic errors can be consistently either positive or negative. The systematic error of the test bed is mainly caused by the structure of the test bed, the limitation of the measuring method and the precision of the test instrument. The effect of random error can be neglected when the geometry and precision of the test bed meet the design requirements. The systematic error of the thrust measurement system is analyzed from the following two aspects.

\section{A. Thrust Line Deflection}

Engine thrust line deflection is mainly caused by the deformation of the load cells, the deflection of the lever, the nonuniformity of exhaust and other factors [7]. As shown in Figure III.

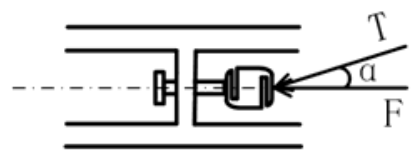

FIGURE III. THRUST LINE DEFLECTION.

Assuming that there is a deflection $\alpha$ between the direction of engine thrust $\mathrm{F}$ and the central axis of two sensors, the measuring sensor is F. So the measurement error

$$
\delta=\left(\mathrm{T}-\mathrm{T}^{*} \cos \alpha\right) / \mathrm{T}=(1-\cos \alpha) * 100 \%
$$

As $\alpha$ is $5^{\circ}, \delta$ is about $0.0001 \%$.

\section{B. Test Instruments and Data Transmission}

The ignition system, the fuel adjustment system and the data acquisition system work simultaneously on the test bench, which can easily affect the thrust signal. We can supply power separately and use shield line in order to reduce the impact on

\begin{tabular}{|c|c|c|}
\hline parameter & unit & value \\
\hline sensitivity & $\mathrm{mV} / \mathrm{V}$ & $2.0 \pm 0.05$ \\
\hline nonlinearity & $\leqslant \% \mathrm{FS}$ & \pm 0.03 \\
\hline hysteresis & $\leqslant \% \mathrm{FS}$ & \pm 0.03 \\
\hline repeatability & $\leqslant \%$ FS & $\pm \mathbf{0 . 0 3}$ \\
\hline creep & $\leqslant \% F S / 30 m i n$ & $\pm \mathbf{0 . 0 3}$ \\
\hline $\begin{array}{l}\text { Zero output } \\
\text { zero }\end{array}$ & $\leqslant \%$ FS & \pm 1 \\
\hline $\begin{array}{l}\text { temperature } \\
\text { coefficient }\end{array}$ & $\leqslant \% \mathrm{FS} /{ }^{\circ} \mathrm{C}$ & \pm 0.003 \\
\hline $\begin{array}{l}\text { Sensitivity } \\
\text { temperature } \\
\text { coefficient }\end{array}$ & $\leqslant \% \mathrm{FS} /{ }^{\circ} \mathrm{C}$ & \pm 0.003 \\
\hline $\begin{array}{l}\text { Temperature } \\
\text { range }\end{array}$ & ${ }^{\circ} \mathrm{C}$ & $-20 \sim+80$ \\
\hline $\begin{array}{c}\text { Input } \\
\text { resistance }\end{array}$ & $\Omega$ & $350 \pm 20$ \\
\hline $\begin{array}{l}\text { Output } \\
\text { resistance }\end{array}$ & $\Omega$ & $350 \pm 5$ \\
\hline Safe load limit & $\leqslant \%$ FS & $150 \%$ \\
\hline $\begin{array}{l}\text { Insulation } \\
\text { resistance }\end{array}$ & M $\Omega$ & $\begin{array}{c}\geqslant 5000 \\
(50 \mathrm{VDC})\end{array}$ \\
\hline $\begin{array}{l}\text { Recommend } \\
\text { excitation }\end{array}$ & $\mathbf{V}$ & $10 \sim 15$ \\
\hline
\end{tabular}
the data transmission.

\section{TABLE I. PARAMETER OF LOAD CELL}


Due to the thermal radiation of the engine, the local temperature has a change of nearly $40^{\circ} \mathrm{C}$, which brings the load cells a temperature drift. To reduce the effect of temperature on the measurement, it needs that the load cell to have a small temperature drift. The CFBLSM-100Kg load cell, whose zero temperature coefficient and sensitivity temperature coefficient are not greater than $0.003 \% \mathrm{FS} /{ }^{\circ} \mathrm{C}$, meeting the accuracy requirements. The parameters of the load cell is shown in Table I.

At the same time, Calculating thrust by a differential method as shown in (3) with data measured from the two load cells can effectively reduces the zero temperature drift and the sensitivity temperature drift.

\section{STATIC CALIBRATION}

The turbojet thrust measurement system needs to be calibrated regularly to ensure measurement accuracy [8]. At present, there are two ways to calibrate the test bench: plane loading and axial loading. Plane loading means that the working sensor is at the same level as the standard sensor and loader, whereas the axial loading is loading directly to the engine thrust axis [9]. Most turbojet engine test bench use the method of plane loading, which is simple to operate, but the calibration status may not be consistent with the measurement status [10]. The axial loading method was used in this test bench though the standard weight. Shown in Figure IV.

Before the testing, a block should be installed at the lower end of the lever to locate the thrust axis. Then we can load on the thrust axial by a fixed pulley, rope and standard weights. Recording the gravity force of the weights as standard values and the thrust values measured by the software on computer as measured values [11].

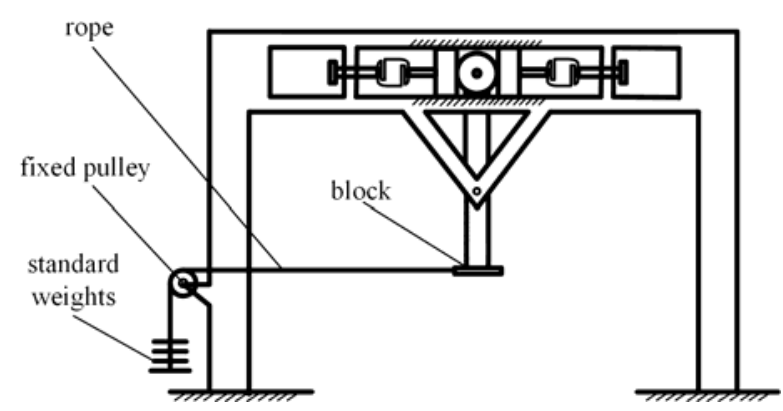

FIGURE IV. STATIC CALIBRATION.

The calibration starts at 0 kilograms and loads in increments of 20 kilograms. At each time it is loaded, the standard value and the measured value are recorded, up to a full scale of 100 kilograms. Then unloading begins with 20 kilograms decreasing each time up to 0 kilograms, recording the standard values and measured values. The above operation was repeated three times, and the average of the six measurements corresponding to each standard value was calculated. If the difference between the average of each calibration point and any one of the (load and unload) records is less than the specified allowable value, the thrust measurement system is considered to be acceptable.

The measured values were averaged, then linear fitting was carried out to obtain the working line equation, so we can calculate the parameters of the test rig. Shown as Table II, the linearity and hysteresis are $\pm 0.06 \%$, the repeatability is $\pm 0.21 \%$. Calibration results show that the thrust measurement system can achieve accuracy of $\pm 0.33 \%$, as $\pm 1.0 \%$ has satisfied the requirement of the test.

TABLE II. RESULTS OF STATIC CALIBRATION

\begin{tabular}{|c|c|c|c|c|c|c|c|c|}
\hline \multicolumn{3}{|c|}{ Load point } & 1 & 2 & 3 & 4 & 5 & 6 \\
\hline \multicolumn{3}{|c|}{ Value of weight(Kgf) } & 0 & 20 & 40 & 60 & 80 & 100 \\
\hline \multirow{6}{*}{$\begin{array}{c}\text { Value of } \\
\text { measurement(Kgf) }\end{array}$} & \multirow[t]{2}{*}{1} & Load & 0.00 & 20.10 & 40.00 & 60.00 & 80.10 & 100.06 \\
\hline & & Unload & 0.00 & 20.00 & 40.10 & 60.03 & 80.00 & 100.00 \\
\hline & \multirow[t]{2}{*}{2} & Load & 0.00 & 20.08 & 40.04 & 60.10 & 80.10 & 100.10 \\
\hline & & Unload & 0.00 & 20.00 & 40.10 & 60.00 & 80.10 & 100.00 \\
\hline & \multirow[t]{2}{*}{3} & Load & 0.00 & 20.10 & 40.00 & 60.00 & 80.10 & 100.10 \\
\hline & & Unload & 0.00 & 20.00 & 40.20 & 60.10 & 80.00 & 100.00 \\
\hline \multicolumn{3}{|c|}{ Average of the load } & 0.00 & 20.09 & 40.01 & 60.03 & 80.10 & 100.09 \\
\hline \multicolumn{3}{|c|}{ Average of unload } & 0.00 & 20.00 & 40.13 & 60.04 & 80.03 & 100.00 \\
\hline \multicolumn{3}{|c|}{ Average of load and unload } & 0.00 & 20.05 & 40.07 & 60.04 & 80.07 & 100.04 \\
\hline \multicolumn{3}{|c|}{ Difference between load and unload } & 0.00 & 0.09 & 0.12 & 0.01 & 0.07 & 0.09 \\
\hline \multicolumn{3}{|c|}{ Full-scale output } & \multicolumn{6}{|c|}{100.04} \\
\hline \multicolumn{3}{|c|}{ Equation of the working line } & \multicolumn{6}{|c|}{$1.0003 * x+0.0275$} \\
\hline \multicolumn{3}{|c|}{ Linearity } & \multicolumn{6}{|c|}{ $\pm 0.06 \%$} \\
\hline \multicolumn{3}{|c|}{ Hysteresis } & \multicolumn{6}{|c|}{ $\pm 0.06 \%$} \\
\hline \multicolumn{3}{|c|}{ Repeatability } & \multicolumn{6}{|c|}{ $\pm 0.21 \%$} \\
\hline \multicolumn{3}{|c|}{ Precision } & \multicolumn{6}{|c|}{ $\pm 0.33 \%$} \\
\hline \multicolumn{9}{|c|}{ Notes: Kgf means kilogram force. The $x$ in equation of working line is values at each load point. } \\
\hline
\end{tabular}




\section{CONCLUSIONS}

This paper introduces a new type of micro-turbojet engine thrust measuring system, which contains the test bench, load cells, data acquisition modules and computer. The test bench has a suspended test bed which is simple and easy to debug. Error analysis has been taken to this thrust measuring system. The effect of random error can be neglected when the geometry and precision of the test bed meet the design requirements. The systematic errors, which comes from the thrust line deflection, test instruments and data transmission, is within the allowable range. The static calibration method of the thrust measurement system is introduced, and the accuracy of the calibration can reach $\pm 0.33 \%$.

\section{ACKNOWLEDGMENT}

The authors are grateful to, among others, Wu Jiang, Zhang Qi, Li Dan, Zheng Xiaolei and technicians of the School of Jet Propulsion of the Beihang University.

\section{REFERENCES}

[1] Xia Yang, Wang Haipeng, Liu Pengpeng and Zuo Hongfu, "Research of on-line monitoring method for small turbojet engine," Aeronautical Manufacturing Technology, pp. 26-29, November 2012.

[2] Yang Quanyan, Yang Jiming, and Han Xiaoquan, "high-precision measuring system for aeroengine thrust," Tansducer and Microsystem Technologies, vol. 27, pp. 82-83, 87, December 2008

[3] Wang Runming,Luo Yi, "Supporting methods for movable stand of aero-engine thrust measurement test bench," Gas Turbine Experiment and Research, vol. 26, pp. 9-11, January 2013

[4] Zhang You, Wu Feng, He Peilei, "Princiole errors analysis of thrust measurement test bench system for aeroengine," Aeroengine, vol. 42 No.4, pp. 76-79, 42, Aug. 2016

[5] Quan Yazhou, "Test bench design of the micro-turbine engine," Changchun University of Science and Technology, 2015.

[6] Wang Huan, Song Jiangtao, Lei Li. Thrust test system design for engine installed on aircraft, Aeronautical Science and Technology, vol. 27, pp. 30-34, January 2016

[7] Jiao Xianrui, "Measuring Error of Thrust," Aviation metrology and measurement technology, vol. 15, pp. 20-22, Apr. 1995

[8] Wu Huiming, "Present and future of calibration of test cell thrust force measuring systenm," Metrology and measurement technology, vol. 32 No.4, pp. 1-3, 13, 2012

[9] Wu Huiming, Jiao Xianrui, "Study of in situ calibration technology of test cell thrust force measuring system," Metrology and measurement technology, vol. 29 No.1, pp. 28-30, 2009

[10] Lei Li, Ye Yaozu, Ma Chang, "Thrust calibration system for aeroengine testing bench," Engineering and Test, vol. 55 No.3, pp. 89-91, Sep. 2012

[11] Huang Zhitao, $\mathrm{Hu}$ Zhengfeng, and Guo Weimin, "The thrust measurement system of the ground test bed of the W 2P1 micro-turbojetengine," Measurement and Control Technology, vol. 18, pp. 40-41, September 1999 